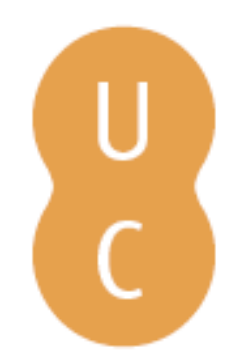

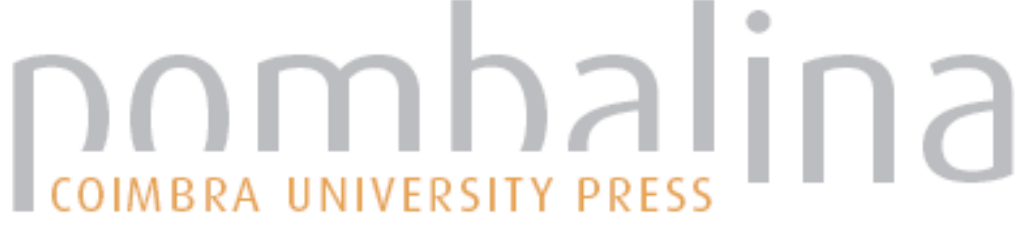

\section{Culturas e povos primitivos de Itália}
Autor(es):
Guerra, Amílcar
Publicado por: Imprensa da Universidade de Coimbra
URL
persistente:
URI:http://hdl.handle.net/10316.2/36909
DOI:
DOl:http://dx.doi.org/10.14195/978-989-26-0954-6_1

Accessed : $\quad$ 26-Apr-2023 07:15:48

A navegação consulta e descarregamento dos títulos inseridos nas Bibliotecas Digitais UC Digitalis, UC Pombalina e UC Impactum, pressupõem a aceitação plena e sem reservas dos Termos e Condições de Uso destas Bibliotecas Digitais, disponíveis em https://digitalis.uc.pt/pt-pt/termos.

Conforme exposto nos referidos Termos e Condições de Uso, o descarregamento de títulos de acesso restrito requer uma licença válida de autorização devendo o utilizador aceder ao(s) documento(s) a partir de um endereço de IP da instituição detentora da supramencionada licença.

Ao utilizador é apenas permitido o descarregamento para uso pessoal, pelo que o emprego do(s) título(s) descarregado(s) para outro fim, designadamente comercial, carece de autorização do respetivo autor ou editor da obra.

Na medida em que todas as obras da UC Digitalis se encontram protegidas pelo Código do Direito de Autor e Direitos Conexos e demais legislação aplicável, toda a cópia, parcial ou total, deste documento, nos casos em que é legalmente admitida, deverá conter ou fazer-se acompanhar por este aviso.

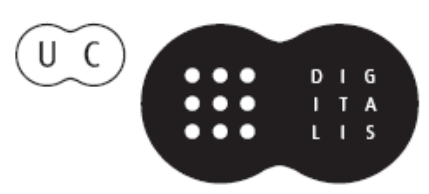


JOSÉ LUÍS BRANDÃO FRANCISCO DE OLIVEIRA (COORD.)

IMPRENSA DA

UNIVERSIDADE

DE COIMBRA

COIMBRA

UNIVERSITY

PRESS
HISTÓRIA DE
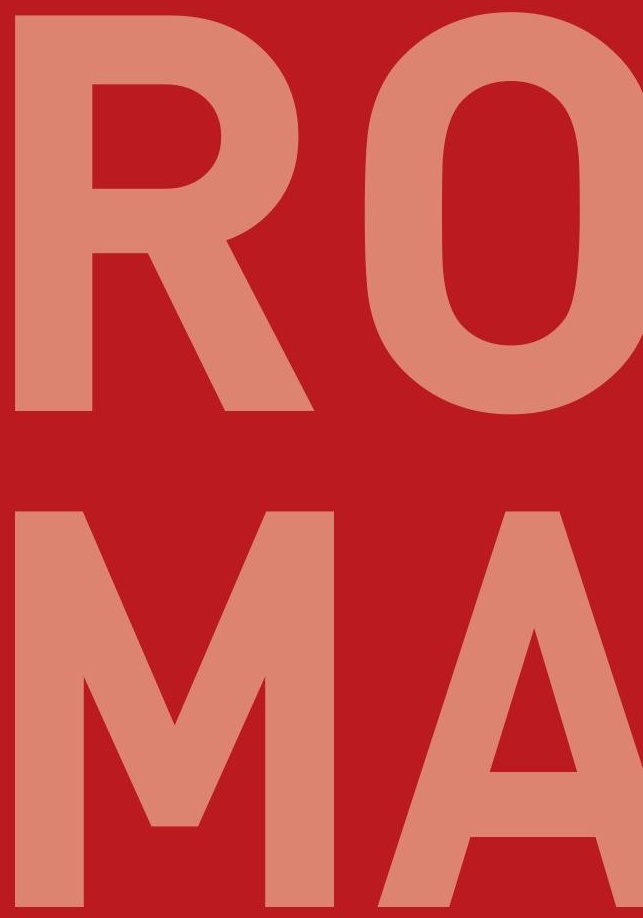

ANTIGA

VOLUME I

DAS ORIGENS À

MORTE DE CÉSAR 


\section{CULTURAS E POVOS PRIMITIVOS DE ITÁLIA}

\section{Amílcar Guerra}

Universidade de Lisboa

Sumário: Contextos histórico-culturais que antecedem a fundação de Roma: culturas lacial e vilanovense. Breve panorama das populações da Itália proto-histórica e respectivas línguas e dialetos. Observações sobre o panorama cultural itálico coetâneo dessa fase primordial da Urbe. Diversidade étnica e linguística das populações que habitam esse território e multiplicidade de entidades que por via da implantação colonial ou do comércio se relacionaram com a Península Itálica nesse período.

\section{Contextos histórico-culturais que enquadram a fundação de Roma.}

\section{A cultura lacial}

O nascimento de Roma, segundo a data tradicional, ocorre num período de pleno desenvolvimento do que se conhece como a cultura lacial No período subsequente ao Bronze Final, na passagem do II ao I milénio, desenha-se no Lácio um quadro complexo, resultado de uma

\footnotetext{
${ }^{1} \mathrm{O}$ adjectivo italiano "laziale", usado para qualificar esta realidade cultural, foi adoptado diretamente em outras línguas como o francês "civilisation / culture latiale", o espanhol "cultura lacial" ou o inglês "latial culture / civilisation", razão pela qual o mantemos a forma correspondente em português.
} 
confluência de tradições apenínicas e locais com elementos exógenos mais ou menos evidentes, entre os quais se destacam, para além dos vestígios orientalizantes mais tardios (séc. VIII-VII), as influências setentrionais da cultura vilanovense e os elementos caraterísticos da chamada Fossakultur de proveniência meridional. O influxo desta última sente-se particularmente num aspecto muito marcante do ritual funerário, conduzindo, a partir de meados do séc. IX, ao progressivo desenvolvimento de práticas de inumação, num contexto em que era habitual incinerar os defuntos ${ }^{2}$. As sepulturas retangulares cavadas na terra ou no tufo integravam por vezes um caixão em madeira associado a uma panóplia de objetos, evidenciando práticas que implicam sacrifícios animais. Tumulações enquadráveis neste âmbito encontram-se, em Roma, nas mais antigas necrópoles do Esquilino e no forum, junto ao templo de Antonino e Faustina, mas também em outras localidades do Lácio, como em Tivoli ou na "Hosteria dell'Osa", em Gábios³.

Denotando uma diversificação dos contactos culturais deste período, o território do Lácio evidencia igualmente os influxos apenínicos, em particular dos seus vizinhos sabinos ${ }^{4}$. Recorde-se que, segundo a tradição, estes teriam dominado o Quirinal, o Capitólio e o pagus Tiberino ${ }^{5} \mathrm{e}$ o seu chefe, Tito Tácio, teria sido mesmo corresponsável, com Rómulo, pela fundação da cidade $^{6}$. Provavelmente a estas populações do interior se devem os vestígios mais conservadores que denunciam a perduração e reelaboração de elementos que remontam ao Bronze Inicial.

\section{A cultura vilanovense ${ }^{7}$}

Durante o período das origens de Roma, estendem-se por uma parte considerável do território itálico, incluindo a zona costeira do Lácio,

\footnotetext{
2 Peroni 1981 ; Quilici 1979 235-236.

3 Quilici 1979 237; Peroni 1989 512-517.

${ }^{4}$ Quilici 1979 238-240; Carandini 1997 343-344.

5 Carandini 1997341.

${ }^{6}$ Poucet 1967 293-327.

${ }^{7}$ Sobre este aspecto, em geral, v. Bartoloni 2002.
} 
os influxos da chamada cultura vilanovense ${ }^{8}$, nome que deriva do sítio paradigmático de Villanova, situado junto a Bolonha, cuja necrópole foi inicialmente escavada por Giovanni Gozzadini, após 1853.

O seu horizonte cultural desenvolve-se a partir do séc. IX a. C. e apresenta-se como continuador de uma tradição que remonta ao Bronze Final, conhecida como o "protovilanovense". Esta última é caraterizada pela sua associação com os campos de urnas, por práticas funerárias de incineração, pelo depósito dos restos em urnas de forma e decoração caraterísticas e pelas amplas evidências de uma apurada metalurgia do bronze.

A cultura vilanovense, que lhe dá seguimento, alarga o seu âmbito de influência, estando os seus restos materiais bem documentados em várias regiões da Península Itálica: a parte meridional da planície do Pó; toda a área da Toscana, especialmente a parte meridional; Lácio, incluindo a própria Roma; Campânia (especialmente Cápua) e área salernitana; alguns territórios da vertente adriática, em particular nas Marcas.

A sua cultura material carateriza-se, em primeiro lugar por enterramentos nos quais predomina claramente, nas primeiras fases, o ritual de incineração e depósito em fossa de urnas funerárias de fabrico manual, bitroncocónicas, cobertas com uma taça, invertida, nas quais, para além dos restos ósseos se acumula um espólio variado. Com estas se depositam as caraterísticas lâminas de barbear em bronze, fíbulas (em particular as de arco serpenteado) e diversos adornos. Progressivamente vão-se afirmando os rituais funerários de inumação. Em fases mais tardias abundam as vasilhas em bronze, algumas particularmente vistosas pela sua decoração, como a sítula de Certosa.

$\mathrm{Na}$ área da Roma antiga e no Lácio a presença de vestígios relacionáveis com a cultura vilanovense patenteia-se em enterramentos nas referidas urnas cinerárias bicónicas de decoração geométrica, mas de motivos bastante variados, alguns deles típicos desta região, as conhecidas urnas em forma de cabana, para além das fíbulas "de sanguessuga", mais difundidas neste contexto.

\footnotetext{
${ }^{8}$ Traduz-se, desta forma, a designação italiana "cultura villanoviana", por vezes também "civiltà villanoviana".
} 
Todos estes elementos assinalam uma dupla realidade: o impacto que essas influências de ampla difusão denotam nesta área e, por outro, o facies peculiar que podem assumir no âmbito do Lácio.

\section{Breve panorama das populações da Itália proto-histórica}

O quadro das entidades étnicas` da Península Itálica nos inícios do I milénio a. C. é bastante diversificado, sendo algo arriscado proporcionar, de forma muito sumária, um panorama desta realidade muito complexa. Referem-se, no entanto, as mais importantes, tratando brevemente as questões do seu âmbito territorial, da sua identidade cultural e linguística.

\section{Ligures}

No panorama das populações antigas da Península Itálica, os Lígures ${ }^{10}$ constituem um dos casos mais problemáticos. Aparecem na literatura clássica como um povo de antiquíssimas origens e essa mesma ideia manteve-se na tradição historiográfica. Embora a sua distribuição geográfica se centre, em período histórico, no noroeste da Itália e sudeste de França, atribuíram-lhes, em momentos anteriores, muito maior amplitude, associando-os a um fundo linguístico constituído especialmente por alguns topónimos e etnónimos. Esses elementos, nem sempre fiáveis, apresentariam uma larga dispersão pelo espaço mediterrâneo e, inclusivamente, pelas costas atlânticas. Na realidade, os reduzidos elementos atestados na região que se lhes atribui não permitem decidir sobre a posição dessa língua no quadro global.

A designação de "lígure" é, por vezes, atribuída a uma outra realidade mais conhecida como lepôntico ${ }^{11}$. A existência, na vertente itálica do arco alpino, de populações falantes de uma língua céltica encontra-se atestada desde fases mais precoces, num conjunto de inscrições grafadas no "alfabeto de Lugano", de ascendência etrusca. De facto, é pacífico que

\footnotetext{
${ }^{9}$ Sobre diferentes povos itálicos v. Pugliese Carrateli ed. 1988; Idem, 1986; Ampolo 1989.

10 Sobre esta entidade v. Pugliese Carratelli ed.1988 159-259.

11 Para esta língua e as suas inscrições v. Lejeune 1988; Prosdocimi ed. 1978 157-204.
} 
corresponde a uma língua céltica continental, documentada num conjunto de epígrafes dispersas numa ampla área que tem como centro geográfico os lagos Maggiore e de Como.

\section{Réticos}

Ao contrário do que acontece com o lígure, não restam dúvidas sobre a natureza do rético ${ }^{12}$, uma língua documentada em cerca de 200 inscrições num alfabeto similar ao venético e, tal como ele, filiado no etrusco. As epígrafes distribuem-se pela zona pré-alpina italiana e pelo arco alpino oriental, abarcando todo o Tirol e Trentino - Alto Ádige, mas estendendo-se até ao Véneto, de Verona a Pádua ${ }^{13}$. Estes documentos atestam uma realidade que se tem aproximado igualmente da língua falada pelos Etruscos ${ }^{14}$, confirmando-se, deste modo, uma filiação que já os autores antigos tinham assinalado ${ }^{15}$.

\section{Etruscos ${ }^{16}$}

A origem dos Etruscos constitui, desde a antiguidade, um tema controverso. As três principais teorias que em boa parte radicam nas considerações dos autores clássicos apresentam-se aos olhos da historiografia com um problema de fundo: a impossibilidade de optar com fundamento por uma das diferentes hipóteses. Na realidade, a questão principal não deve situar-se nesse plano, mas em perceber o processo de desenvolvimento cultural das comunidades que desde o Bronze Final se identificam como etruscas, que a arqueologia moderna associa com a cultura vilanovense ou com o seu antecedente.

Os Etruscos, em torno do quais se desenvolveu em determinado período a ideia de possuírem uma língua tão misteriosa quão proble-

12 Um corpus das inscrições em Mancini 2009-2010.

13 Morandi 199936.

${ }^{14}$ Rix 1998 propõe a designação de "línguas tirsénicas" para designar um grupo constituído pelo etrusco, o rético e a língua de Lemnos. G. Facchetti 2002 alarga este grupo a algumas línguas antigas do Egeu (minoico, eteocretense), de Chipre e da Palestina (filisteu).

15 V. g. Plin. Nat. 3.133 - /.../ considera-se que os Récios são descendentes dos Etruscos /.../. Esta mesma ideia se encontra em outros aa. clássicos v. Morandi ibid.

16 Sobre este povo, em geral, v. Pugliese Carratelli ed. 1986. 
mática constituem, sem dúvida, a mais notável das entidades itálicas que integram o grupo dos que não possuem uma língua indo-europeia. Graças ao número elevado de textos (mais de 9000) e às possibilidades de confrontação com outras realidades conhecidas perdeu esse caráter enigmático, permitindo a sua descrição parcial, nos planos morfológico, sintático e semântico ${ }^{17}$. Torna-se, por isso, viável uma compreensão, pelo menos parcial, do conteúdos dos documentos que a atestam.

Para além do etrusco, um antigo falar não integrável no domínio indo-europeu atestar-se-a na área setentrional do Piceno, conhecido como "língua picena setentrional" ou "da estela de Novilara" e a respeito do qual a informação se revela ainda muito escassa e problemática.

\section{Messápios}

Uma outra componente muito particular das populações itálicas ocupa a parte meridional das costas adriáticas, da qual fazem parte os Messápios ou Iapígios ${ }^{18}$ que ocupam grosso modo o que será a atual região da Apúlia. Na sua aceção mais ampla, registada nas fontes clássicas (Plb. 3.88; Th. 7.33), o termo abarca Dáunios, Peucécios ${ }^{19}$ e Iapígios, na ordenação de norte para sul, cabendo a estes últimos, também chamados Messápios, em sentido estrito, o extremo da península.

Atribui-se-lhes uma origem ilírica, tendo especialmente em conta as fontes clássicas e o que se conhece da sua língua, o messápico ${ }^{20}$. Em sentido mais restrito, a península salentina, onde se situa a maioria dos seus vestígios ${ }^{21}$.

A documentação que lhe diz respeito consiste essencialmente numas centenas de inscrições que adotam um alfabeto afiliado no grego, em especial numa variante lacónico-tarentina ${ }^{22}$, com ligeiras adaptações que

17 Da extensa bibliografia sobre a língua, pode ver-se uma apresentação geral em Bonfante - Bonfante 2002.

18 Esta identidade é reconhecida em Str. 6.3.1; 6.3.5, mas contrariada em Plb. 2.24.10.

19 Os vestígios correspondentes especificamente aos Dáunios e Peucécios, mas são raros e mais tardios (De Simone 1979 105-106).

${ }^{20}$ v. De Simone; Marchesini 2002; De Simone 1992.

21 De Simone 1979105.

22 De Simone 1972177. 
se traduziram essencialmente na introdução de um número reduzido de novos signos, destinados a suprir as carências do sistema de signos. Cronologicamente, os materiais epigráficos abarcam um arco cronológico que vai dos finais do séc. VI ao II a. C.

Os nossos conhecimentos sobre a sua língua são muito limitados, uma vez que restringindos quase exclusivamente a antropónimos reportados sobretudo por inscrições funerárias ou grafitos em objetos cerâmicos. Os elementos disponíveis têm levado alguns autores a postularem a integração desta língua indo-europeia no grupo ilírico. No entanto, as fortes incertezas a respeito das realidades linguísticas, designadas como ilíricas, do outro lado do Adriático recomendam que não se atribua o messápio a uma família concreta.

\section{Vénetos}

$\mathrm{Na}$ parte setentrional da costa adriática regista-se a presença de populações venéticas ${ }^{23}$. A tradição clássica atribui-lhes uma origem exógena, conjecturando hipóteses de migrações a partir de várias regiões da Ásia Menor ou da região ilírica ${ }^{24}$, algumas das quais obtiveram crédito de alguma historiografia moderna. No entanto, o mais provável é que correspondam a populações há muito instaladas no território itálico, pelo menos desde a Idade do Bronze. Para tal conclusão contribuiu a natureza da sua língua, o venético ${ }^{25}$, uma língua indo-europeia antiga que se costuma integrar no grupo itálico ${ }^{26}$. Alguns autores, todavia, embora reconheçam as afinidades com as línguas antigas dessa família, consideram não existir dados que permitam sustentar a sua integração nela.

A documentação pertinente corresponde em particular a inscrições, atestadas inicialmente numa variante setentrional do alfabeto etrusco ${ }^{27} \mathrm{e}$

23 As questões de cultura e língua podem ver-se em Fogolari - Prosdocimi 1987.

${ }^{24}$ Nomeadamente em Plb. 2.17.5; Str. 4.1.1.; 12.3.8; Plin. Nat. 3.130; Liv. 1.1.1-3; Verg. Aen. 1.245-252)

25 Sobre esta realidade v. Lejeune 1974; Wallace 2004.

26 O termo designa aqui um larga família de línguas indo-europeias da Península Itálica: latim, falisco, sículo, osco-úmbrico e não se limita, como é prática em alguns autores, a esta última realidade.

27 Lejeune 197421. 
mais tardiamente em carateres latinos. Estes documentos que ocorrem num espaço compreendido aproximadamente entre curso do Pó, área em que a concentração é maior ${ }^{28}$, e o atual território de fronteira entre a Itália e a Eslovénia. Estes vestígios ajudam a delimitar de forma mais precisa o que poderia constituir o âmbito geográfico desta entidade.

\section{Sículos}

Os Sículos aparecem em período histórico na Sicília oriental, compondo, segundo as fontes, um quadro variado de populações que em diferentes épocas aí se instalaram. Aponta-se-lhes uma origem na Península Itálica, esclarecendo Tucídides ${ }^{29}$ que a sua movimentação era muito antiga e se deveu a uma pressão dos Ópicos (Th. 6.2), enquanto Dionísio de Halicarnasso (D.H. 1.9) vê neles os primeiros habitantes de Roma, expulsos por uma aliança entre os aborígenes e os Gregos. A arqueologia tem associado o estabelecimento dos Sículos no seu novo território insular à presença de um conjunto de vestígios materiais enquadráveis no protovilanovense (achados em Milazzo $^{30}$ ), com uma cronologia que corresponde aos finais do $2 .^{\circ}$ milénio.

As considerações das fontes clássicas sobre a sua origem parecem encontrar apoio na historiografia moderna, em especial em algumas observações de natureza linguística. De facto, alguns estudiosos atuais, para além de aceitarem como relativamente pacífico que o sículo, falado em período histórico na Sicília oriental, é uma língua indo-europeia, sustentam as suas afinidades com o latim e o falisco ${ }^{31}$, integrando-a, portanto, no grupo itálico. No entanto, são igualmente patentes algumas similitudes com o osco-úmbrico. Todavia, o nosso desconhecimento a respeito do sículo recomenda uma postura cautelosa.

28 Verifica-se uma especial incidência junto à localidade de Este, onde se desenvolve uma escrita particular (Lejeune 1974, 25-28).

29 Th. 6.2.5. situa-a 300 anos antes do início da colonização grega, isto é, no séc. XI, uma proposta um pouco mais tardia que a de Elânico de Lesbos, que a coloca antes da guerra de Tróia.

30 Bernabò Brea; Cavalier1956.

31 Devoto 1959, inclui-a no âmbito latino, a que pertencem estas últimas, distanciando-a de um outro conjunto que engloba o osco-úmbrico e outras realidades afins. 


\section{Picenos}

Numa faixa não muito larga da costa adriática, ocupando um espaço que se reparte entre as regiões italianas das Marcas e, parcialmente, dos Abruzos, numa extensão de aproximadamente $200 \mathrm{~km}$, costuma situar-se uma realidade cultural que se designa como a "civilização picena". Para designar os habitantes desta região as fontes clássicas alternam entre a forma Piceni e Picentes $^{32}$. Segundo a tradição literária ${ }^{33}$ esta entidade corresponderia a sabinos emigrados (Str. 5.3.1; Plin. Nat. 3.110), que, de acordo com o texto pliniano, teriam empreendido uma incursão nessa região na sequência de um ver sacrum ${ }^{34}$.

Os mais antigos vestígios que conferem identidade a este mundo remontam ao séc. IX, originalidade que se prolonga até ao momento dos contactos mais estreitos com Roma. Para além de se conhecerem as necrópoles, foram identificados também os povoados, ainda que o nosso conhecimento atual destas últimas realidades se encontre mais limitado pela falta de trabalhos arqueológicos.

$\mathrm{Na}$ área atribuída a esta entidade atestam-se vestígios de pelo menos duas línguas: na parte setentrional uma, a que se aludiu, considerada geralmente não indo-europeia; na parte meridional, uma outra que pertence ao domínio linguístico osco-úmbrico. Ainda que esta última se encontre atestada num número escasso de documentos ${ }^{35}$, a sua integração no âmbito dos dialetos sabélicos ${ }^{36}$, do grupo a que se aludiu acima, é geralmente aceite.

\section{Umbros}

A sul dos Picenos, ocupando as áreas apenínicas centrais da Itália, dominava um conjunto de populações com amplas afinidades culturais, para os quais alguns autores usam o termo Sabélicos ${ }^{37}$. Quando se tra-

32 Esta forma, mais rara, atesta-se já nos Fast. cos. cap. (268-267 a. C.) e também em Plb. 2.21.7; 3.86 .8 e Var. $R R$ 1.2.7, citando uma afirmação de Catão o Censor.

33 Para a sua análise v. Antonelli 2003.

34 Festo, nas suas explicações etimológicas (Fest. 235 L), especifica que nos seus estandartes teria pousado um pica-pau, ave do qual retiraram o nome, explicando Estrabão (Str. 5.4.2.) que se trata de uma ave dedicada a Ares.

35 Para esta documentação v. Marinetti, 1999.

36 Para a documentação relativa a este conjunto de realidades v. Rix 2009; Untermann 2002.

37 No entanto, este termo tem outras aceções distintas, usando-se por vezes para designar especificamente os Samnitas. 
ta de individualizar as realidades étnicas mais antigas deste conjunto, apresentam-se essencialmente os Umbros, Oscos e Picenos, seguindo uma subdivisão baseada na evidência linguística.

Os Umbros, segundo a enciclopédia pliniana um antiquíssimo povo da Itália (Plin. Nat. 3,112), apresentam-se como uma entidade que ocupa, em período proto-histórico, uma boa parte do Apenino Central, bem como algumas áreas adjacentes, tanto na vertente adriática como na tirrénica. Ao longo do primeiro milénio o seu território sofrerá oscilações substanciais, devido à pressão de vários povos, em especial de Etruscos e Gauleses, até à sua submissão aos romanos. Uma das principais marcas da sua individualidade reside na sua língua, atestada por um conjunto de documentos, tanto em alfabeto próprio, subsidiário do etrusco, como no latino, de entre os quais sobressaem as famosas Tabulae Iguvinae. $\mathrm{Na}$ realidade, os falares úmbricos são bastante diversos, abarcando em especial os dialetos falados no sul do Piceno, o sabino, o marso, o volsco e o chamado pré-samnita.

\section{Oscos}

O conjunto de populações designadas como oscas ocupava um território que continuava o dos Umbros, correspondendo a uma boa parte do território meridional da Península Itálica. Existe uma substancial divergência no que respeita às relações entre as múltiplas entidades que integrariam este nome de natureza mais genérica. Em parte porque, à medida que se multiplicam as referências dos autores clássicos aos povos itálicos, o quadro se torna cada vez mais complexo.

Os seus vestígios epigráficos entre os quais sobressaem a tábua de Bântia e o cipo de Abela foram grafados em diversos alfabetos: etrusco, grego e latino.

No plano linguístico, o panorama define-se, por uma relativa unidade que se consagra na existência de uma língua osca, dominante no território itálico meridional no período da conquista romana desses territórios. De qualquer modo, no seu âmbito se definem alguns dialetos que de alguma forma traduzem a diversidade desse mundo, especialmente o hérnico, o marrucino, o samnita e o peligno (Marinetti 1999; Prosdocimi 1978 825-912). 


\section{Latinos}

Como se viu, a realidade histórico-cultural coetânea da fundação tradicional de Roma associa-se, no plano arqueológico, ao que se designa como a "cultura lacial". Nela se integram as diferentes comunidades do antigo Lácio, em particular os territórios de Roma e o dos Montes Albanos, no âmbito dos quais se situava a cidade de Alba Longa (ligada à ocupação dispersa pelo sudoeste do Lago Albano), cidade que, segundo uma tradição recolhida por Dionísio de Halicarnasso e retomada na epopeia virgiliana (Verg. Aen. 1.267), teria sido fundada por Ascânio /Julo. Por outro lado, também Lavínio (atual Pratica di Mare, junto à costa tirrénica), lugar onde teria aportado Eneias, se configuraria como outro dos núcleos importantes deste passado remoto que associam uma forte tradição mítica com os vestígios materiais de um presença humana precoce.

Para além das afinidades que se revelam nos restos materiais, a estas populações se ligam igualmente tradições religiosas que se assumem, em determinado momento da organização federal destas comunidades, como um património comum. Talvez o caso mais conhecido seja o santuário de Diana de Arícia, junto ao Lago de Nemi, onde, para além de um templo mais recente, se atestam vestígios que remontam aos inícios do I milénio a. C.

Outro elemento de ligação destas comunidades residia na sua língua, cuja versão romana se veio a difundir com a expansão territorial da Urbe. Naturalmente, nenhum dos falares latinos, algo diferenciados entre si, se pode comparar com o que conhecemos da língua de Roma, uma vez que das outras realidades dialetais do Lácio, como o prenestino ou o lanuvino, pouco nos chegou.

\section{Faliscos}

Entre as múltiplas entidades da Itália contemporâneas das origens de Roma encontra-se uma, de pequena dimensão, mas cuja individualidade se encontra bem documentada, não apenas por aspetos de natureza arqueológica e histórica, mas também pela sua língua. Os Faliscos eram vizinhos da Urbe, uma vez que a sua cidade mais importante, Falérios (atual Cività Castellana), distava dela cerca de $70 \mathrm{~km}$. O seu território, na 
margem direita do Tibre, confrontava igualmente, em período histórico, com os Etruscos, em particular com Veios, e com os Sabinos.

Conhecem-se cerca de uma centena de inscrições, num alfabeto similar ao latino arcaico, que transcrevem a língua local, muito fragmentariamente atestada ${ }^{38}$. O falisco constitui uma realidade cuja posição no quadro linguístico da Itália antiga não deu lugar a muitas controvérsias, assumindo-se como relativamente pacífico que se trata de uma realidade com grandes afinidades com as línguas das populações latinas ${ }^{39}$. Alguns autores sublinham, todavia, algumas peculiaridades que a aproximam do osco-úmbrico ${ }^{40}$, com o redobro do perfeito, o que é natural num quadro evolutivo próprio em que alguns traços conservadores se podem manter. Alguns autores identificaram ainda algumas influências, especialmente na grafia e na fonética, devidas ao contacto com o mundo etrusco ${ }^{41}$.

Este quadro, muito simplificado, resume um panorama cultural e linguístico muito complexo e em relação ao qual, com frequência, escasseiam os dados. Compreendem-se, deste modo, as incertezas sobre muitos dos aspetos tratados e a diversidade das interpretações que historiadores e linguistas patenteiam.

\section{Bibliografia}

Ampolo, C. et al. (1989), Italia omnium terrarum parens. Milano, Scheiwiller.

Antonelli, L. ed. (2003), I Piceni: corpus delle fonti, la documentazione letteraria. Roma, L'Erma di Bretschneider.

Bakkum, G. C. L. M. (2009), The Latin Dialect of the Ager Faliscus: 150 Years of Scholarship. Amtserdam, Universiteit.

Bartoloni, G. (2002) - La cultura villanoviana. Roma, Carocci.

38 V. Giacomelli 1978 e, mais recentemente, Bakkum 2009.

39 Campanile, no entanto, sublinhou o seu caráter conservador e pôs em evidência algumas afinidades com os grupos germânico e céltico (Campanile1968 55-58), apontando para uma eventual autonomia em relação ao conjunto dos falares latinos (Campanile 1969 92).

40 Giacomelli 1978 522-523. Solta 1974 45-47 vai mais longe, considerando-a mesmo uma língua osco-úmbrica.

41 Nem todas, contudo, são pacíficas. Giacomelli 1978 considera a perda da distinção $f / h$ um dos exemplos desta influência, mas outros preferem pensar que se trata de um traço distintivo próprio, não influenciado por uma realidade exógena. 
Bernabò Brea, L., Cavalier, M. (1956), "Civiltà preistoriche delle Isole Eolie e del territorio di Milazzo", Bullettino di Paletnologia Italiana 67 7-98.

Bonfante, G., Bonfante, L. (2002), Etruscan language, revised edition. Manchester, University Press.

Campanile, E. (1968), "Studi sulla posizione dialettale del latino", SSL 8 16-130.

Carandini, A. (1997), La nascita di Roma: dèi, lari e uomini all'alba di una civiltà. Torino, Einaudi.

Devoto, G. (1959), "Siculo e protolatino", SE 27 141-150.

Facchetti, G. M. (2002), "Appendice sulla questione delle affinità genetiche dell'Etrusco" in Appunti di morfologia etrusca. Firenze, Olschki 111- 150.

Fogolari, G., Prosdocimi, A. L. (1987), I veneti antichi : lingua e cultura. Padova, Studio Editoriale Programma.

Giacomelli, G. (1978), "Il falisco" in Populi e civiltà dell'Italia antica, vol. VI: Lingue e dialetti. Roma 505-542.

Lejeune, M. (1974), Manuel de la langue vénète. Heidelberg, Carl Winter.

Lejeune, M. (1988), Recueil des inscriptions gauloises: II.1 Textes gallo-étrusques. Textes gallo-latins sur pierre. Paris, CNRS.

Mancini, A. (2009-2010), Iscrizioni retiche. 2 vol. Padova, Unipress.

Marinetti, A. (1999), "Le iscrizioni sudpicene" in I Piceni, popolo d'Europa. Roma 134-138.

Morandi, A. (1999), Il cipo di Castelciès nell'epigrafia retica, Roma, L'Erma di Bretschneider.

Peroni, R. (1989), Protostoria dell'Italia continentale: La Penisola italiana nelle Età del Bronzo e del Ferro. Roma.

Poucet, J. (1967), Recherches sur la légende sabine des origines de Rome. Louvain, Université.

Prosdocimi, A. ed. (1978), Populi e civiltà dell'Italia antica, vol. VI: Lingue e dialetti. Roma.

Pugliese Carratelli, G. ed. (1986), Rasenna. Storia e civiltà degli Etruschi. Milano, Scheiwiller.

Pugliese Carratelli, G. ed. (1988), Italia, omnium terrarum alumna. Milano, Scheiwiller.

Quilici, L. (1979), Roma primitiva e le origini della civiltà laziale. Roma, Newton-Compton.

Rix, H. (1998), Rätisch und Etruskisch. Innsbruck, Universität.

Rix, H. ed. (2009), Sabellische Texte: die Texte des Oskischen, Umbrischen und Südpikenischen. Heidelberg, K. Winter.

Simone, C. de (1992), "La lingua messapica: tentativo di una sintesi" in Atti XI Convegno di studio della Magna Grecia, Taranto 1971. Napoli 125-201.

Simone, C. De, Marchesini, S. (2002), Monumenta linguae messapicae. Wiesbaden

Solta, G. R. (1974), Zur Stellung der lateinischen Sprache. Wien, Österreichische Akademie der Wissenschaften.

Untermann, J. (2000), Wörterbuch des Oskisch-Umbrischen. Heidelberg, K. Winter.

Wallace, R. E. (2004), "Venetic" in Woodard, R. D., The Cambridge Encyclopedia of the world's ancient languages. Cambridge, University Press 840-856. 